\title{
Health sector leadership in mitigating climate change: experience from the UK and NSW
}

\author{
David Pencheon $^{\mathrm{A}}$, Chris E. Rissel ${ }^{\mathrm{B}, \mathrm{E}}$, Glen Hadfield ${ }^{\mathrm{C}}$ and D. Lynne Madden

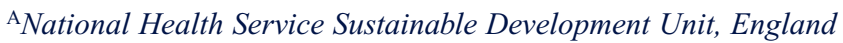 \\ ${ }^{\mathrm{B}}$ Health Promotion Service, Sydney South West Area Health Service, University of Sydney \\ ${ }^{\mathrm{C}}$ Sydney West Area Health Service \\ ${ }^{\mathrm{D}}$ Royal Australasian College of Physicians \\ ${ }^{\mathrm{E} C o r r e s p o n d i n g ~ a u t h o r . E m a i l: ~ c r i s s @ e m a i l . c s . n s w . g o v . a u ~}$
}

\begin{abstract}
The threat to human health from climate change means that all levels of government and private and public agencies will need to change their current practices to reduce carbon emissions. The health sector will also need to respond and change practice. The National Health Service in the United Kingdom is developing a systematic and strategic approach to reduce its carbon footprint, as described in the recently released NHS Carbon Reduction Strategy for England. The work is being led by the Service's new Sustainable Development Unit. While the Australian health care system has not yet embraced a shared vision for carbon reduction, there are examples emerging of how the sector is contributing to reduce greenhouse gas production. Examples from two NSW area health services to reduce energy use and promote active transport are presented. In both countries, these changes are supported by new legislation and policy.
\end{abstract}

There is a strong international scientific consensus about the consequences of the warming of the world's climate system with a recent Lancet editorial arguing that "climate change is the biggest global health threat of the 21 st century'. ${ }^{1-3}$ A rise of more than $2 \%$ in the earth's average surface temperature will have significant health and social costs for Australia. ${ }^{4}$ Urgent international action is required; within Australia action is required by all levels of government, across all sectors and by individuals, to avoid the potential consequences. Professor Tony McMichael, a member of the United Nations Intergovernmental Panel on Climate Change, stated 'We are not talking just about regrettable collateral damage. These health risks signify something profound - the potential of climate change to undermine the foundations of our wellbeing, health and survival. ${ }^{5}$

This article presents arguments for why and how the health sector can respond to the threat posed by climate change. It highlights the work of the newly established Sustainable Development Unit of the United Kingdom's National Health Service (NHS) and the 2009 Carbon Reduction Strategy for England. ${ }^{6}$ It is consistent with the 2008 World Health Organization's general recommendations for how the health sector might achieve carbon savings. ${ }^{7}$ Local examples from area health services (AHSs) in New South Wales (NSW) of carbon reduction initiatives are highlighted.

\section{NHS Sustainable Development Unit}

The Sustainable Development Unit focuses on carbon reduction by the NHS with the intention 'to meet our needs today without compromising the ability to meet our needs and the needs of others - today and tomorrow'. ${ }^{6}$ The Unit has been established to: inform and shape policy around promoting sustainable development and reducing carbon 
emissions in the NHS; engage in primary and secondary research to measure changes in carbon use; examine changes in carbon use that will occur up to 2050 and how the NHS can manage those changes; and to develop and promote this agenda.

\section{Why the UK health sector needs to act}

There are many reasons why the health sector should act to mitigate climate change. Some of these reasons are:

1. The 2008 Climate Change Act for England has set a target of an $80 \%$ reduction in carbon emissions on 1990 baseline levels by $2050 .^{8}$ To achieve this target, a transformational change is required by the health sector.

2. Within an evidence-based health system, there is an imperative to respond to the immediate threat of climate change in light of the scientific evidence of the need to reduce carbon emissions. ${ }^{1}$

3. Some strategies to reduce carbon emissions create opportunities for immediate health co-benefits, especially in the way we promote how we move (active transport such as walking and cycling) and how we eat (a more balanced diet including less meat/dairy).

4. There are financial savings to be made from reduced energy costs from reducing the use of energy.

5. It is important that the health sector continues to be resilient and robust, responding to changes in the political and social environment.

6. Consultation with health workers has demonstrated their commitment to addressing climate change. ${ }^{9}$

7. There is a special responsibility and opportunity for the health sector to lead by example.

The vision for UK health services in the next 50 years is congruent with a low carbon society. Providing improved management of chronic diseases, delivering convenient care closer to home and the better use of technology are themes associated with both saving resources and improved health care.

\section{Health co-benefits from reducing carbon use in the health sector}

There are three levels of health co-benefits from reducing carbon use. First, there are the benefits from initiatives such as active travel, including personal health benefits from being more physically active, and, because fewer cars are being driven, reduced traffic congestion and air pollution. Secondly, there are benefits from a more sustainable health care system, which is congruent with health care policy developments such as care closer to home, chronic disease management and self care. Thirdly, there are benefits for international health equity if developing countries can move from pre-carbon economies to post-carbon systems, avoiding a period of heavy carbon use. Climate change makes these developments that the health sector is already engaged with, even more compelling.

\section{The carbon footprint of the NHS}

The NHS is one of the largest employers in the world; it is also a large procurer of goods and services from local, national and international economies. Consequently it is often the biggest single employer in regional areas and forms a significant component of the regional economy.

Reflecting its size, the NHS is responsible for 20 million tonnes of carbon dioxide per annum. It is the largest public sector contributor to climate change in England, producing $25 \%$ of public sector emissions which is equivalent to the emissions of an entire medium-sized country. ${ }^{10}$ The NHS carbon footprint is composed of energy (heating, lighting, hot water and ventilation; 22\%), travel (staff, patients and visitors; 18\%) and procurement (the supply chain of activities producing goods and services used by the health system; 60\%). ${ }^{10}$ Despite an increase in efficiency, the NHS has increased its carbon footprint by $40 \%$ since $1990 .{ }^{10}$ This means that meeting the Climate Change Act targets of a $26 \%$ reduction by 2020 and an $80 \%$ reduction by 2050 will be a challenge. The 2009 Carbon Reduction Strategy establishes that the NHS should have a target of reducing its 2007 carbon footprint by $10 \%$ by 2015 . This will require the current level of growth of emissions to not only be curbed, but also for the trend to be reversed and absolute emissions reduced. Interim NHS targets will need to meet the government targets.

This will require transformational change management beyond that required to master the technical aspects of using less carbon; organisational structures, responsibilities and accountabilities within the NHS are being reconsidered to ensure that change happens. Consequently, while the move to a more sustainable health system will need to be driven at all levels, the commitment from the top levels of management is essential.

\section{The challenge to reduce the NHS carbon footprint}

Steps the NHS has already taken to reduce carbon include measuring, monitoring and displaying what energy is currently being used in health facilities. ${ }^{11}$ This helps to increase carbon literacy and carbon numeracy of health care workers and patients, and reduce carbon use. Another strategy is to promote low-carbon transport like car sharing by offering reduced parking costs for car-sharing arrangements. As in all change programs, there has to be an immediate benefit to those doing the changing. Prominent programs like car sharing or parking spaces for bicycles also send a visible and important message to the public that the health system takes carbon reduction seriously.

Influencing the commissioning and procuring of goods and services is essential to carbon reduction because of the 
emissions associated with procurement. NHS contracts now include statements such as 'criteria relating to sustainability and low carbon operations will increasingly be used in the commissioning of services and the procurement of goods'. The buying power and potential leverage of the health sector is significant and can have considerable knock-on effects throughout the community through the goods and services it buys or commissions. This is important because of the multiplier effect through the supply chain.

\section{The carbon footprint in the NSW health sector}

In NSW, health facilities account for $53 \%$ of the total NSW Government building energy usage. ${ }^{12}$ For example, in the Sydney West Area Health Service in 2007-2008, 106 gigawatt hours of electricity and 348 terajoules of gas were used, equivalent to the use of a city the size of Lithgow. ${ }^{13}$ It also used 665 megalitres of water, about the amount of 1.5 Olympic-sized swimming pools per day. This water and power cost $\$ 11.3$ million per year to purchase and caused 125000 tonnes of carbon dioxide to be emitted into the atmosphere, equivalent to the emissions of about 25000 cars. ${ }^{13}$ The cost of these utilities is also expected to rise from between 12 and $35 \%$, adding further pressure to reduce energy use and the associated costs.

The NSW Government Sustainability Policy proposes: reducing greenhouse gas emissions from buildings to 2000 levels by 2020 ; a $15 \%$ reduction in water usage; that all products and appliances purchased to be 4.5-energystar rated; and a renewable energy target of $20 \%$ by $2020 .^{12}$ However, many in the health sector workforce are unaware of these targets. A shift in thinking that prioritises a smaller carbon footprint will be required across the whole Australian population and, equally, will need to be applied within the health sector workplace.

\section{NSW initiatives}

\section{Sydney West Area Health Service - Energy}

Blacktown, Mount Druitt and Nepean Hospitals are now generating $40-50 \%$ of their electricity onsite using cogeneration fired by natural gas. This has resulted in an average $15 \%$ reduction in electricity consumption across the Sydney West Area Health Service (SWAHS). Twenty thousand energy efficient light fittings have been installed across SWAHS facilities. ${ }^{14}$ An independent audit has demonstrated that the area has reduced its carbon emissions by over 8000 tonnes in 2007-2008, and energy efficient upgrades at Westmead Hospital (the largest teaching hospital within the area) have compensated for the additional electricity consumption associated with the opening of two new buildings. In 2005, SWAHS was the first AHS in NSW to become a carbon trader, earning 22286 NSW Greenhouse Abatement Certificates to date, equivalent to a reduction of 22286 tonnes of carbon emissions. ${ }^{14}$
While these energy saving projects require investment to implement, they are usually responsible for recurrent savings. For example, at Westmead Hospital a lighting upgrade that cost approximately $\$ 2$ million is estimated to save about $\$ 300000$ each year with a net financial benefit anticipated after 7 years. Similarly, a water recycling project that cost about $\$ 2.5$ million is expected to save about $\$ 215000$ each year. Generally speaking, energy consumption can be reduced by up to $25 \%$, with a relatively easy $10 \%$ reduction achieved through lighting upgrades.

SWAHS have completed a series of large-scale energy efficiency upgrades over the past 5 years and are now planning a series of further projects. Using Energy Performance Contracting a detailed audit of a facility is first undertaken to identify the opportunities for energy and water savings. ${ }^{15}$ A business case is then prepared, which leads to a project proposal based on guaranteed savings.

The projects completed by SWAHS represent an investment of $\$ 13$ million in new energy and water efficient infrastructure with savings estimated to be over $\$ 1.8$ million every year. The scope of projects covered includes all the major AHS facilities, consisting of nine hospitals and 11 Community Health Centres.

\section{Sydney South West Area Health Service - Transport}

Health services generate an enormous number of trips to and from facilities every day. As previously described, how people travel can directly influence both their carbon use and their health. A strategy to reduce car use trialled by the Sydney South West Area Health Service has been the development of transport access guides for major trip generators such as hospitals. ${ }^{16}$ These guides illustrate how to travel to and from the hospitals using active travel by showing: where the cycle paths are; recommended walking routes from rail stations; locations of bus stops; and an indication of the frequency of buses. By not showing car parking stations and making active travel easier, this strategy is intended to influence the decision of how to travel to these destinations.

Another strategy has been to work with local cycling groups to develop cycling specific maps to highlight cyclist preferred routes to and from health facilities. ${ }^{17}$ Other activities to encourage greater levels of cycling have included: working with local councils on developing Bicycle Plans; the development of a cycling proficiency course to increase the skills and confidence of people wanting to cycle more; and the development of a staff bicycle pool. ${ }^{18-20}$

\section{Health professionals as agents for change}

As respected members of the community, health professionals can have a large influence on opinion. Their 
numbers and geographic dispersion throughout the population, as well as their clinical and social networks, ensure contact with almost everyone in a local population. ${ }^{21,22}$ Health professionals have an important role in supporting an environment for change within the health sector and evidence from the NHS suggests that this a role they would welcome. ${ }^{6}$

\section{Conclusion}

The threat to human health from climate change means that all levels of government and private and public agencies will need to change their current practices to reduce carbon emissions. All Australians will need to play a part in creating a healthy future and will need to fundamentally change the way they think and live. While the Australian health care system has not yet embraced the challenge of reducing its carbon footprint from a whole systems perspective as the NHS has done, there are many local examples of leadership in NSW.

\section{Acknowledgment}

This paper is based on the Australasian Faculty of Public Health Medicine's Redfern Oration and two other keynote presentations in the Faculty's Plenary Session, held during the Royal Australasian College of Physicians' 2009 Physicians Week in May.

\section{References}

1. Intergovernmental Panel on Climate Change. Climate Change 2007: Impacts, Adaptation and Vulnerability. Contribution of Working Group II to the Fourth Assessment Report of the Intergovernmental Panel on Climate Change. Parry ML, Canziani OF, Palutikof JP, van der Linden PJ, Hanson CE, editors. Cambridge, UK: Cambridge University Press; 2007.

2. Costello A, Abbas M, Allen A, Ball S, Bell S, Bellamy R et al. Managing the health effects of climate change. Lancet 2009; 373(9676): 1693-733. doi:10.1016/S0140-6736(09)60935-1

3. Editors. A Commission on climate change. Lancet 2009; 373(9676): 1659. doi:10.1016/S0140-6736(09)60922-3

4. CSIRO, Australian Bureau of Meteorology. 2007. Climate change in Australia: technical report 2007. CSIRO. Available from: http://www.csiro.au/resources/ps3j6.html (Cited 7 August 2009.)

5. McMichael T. Health risks of climate change: we all need to be involved. RACP News 2009; June: 5-7.

6. Sustainable Development Unit. Saving Carbon, Improving health: NHS Carbon Reduction Strategy for England. Cambridge, UK: NHS Sustainable Development Unit; 2009.

7. World Health Organization. Protecting health from climate change - World Health Day 2008. Available from: http://www.who.int/world-health-day/toolkit/report_web.pdf (Cited 22 July 2009.)

8. Climate Change Act. 2008 (c. 27). London: Her Majesty's Stationery Office.
9. Sustainable Development Unit. Consultation on Draft Carbon Reduction Strategy for England. NHS Sustainable Development Unit; 2008. Available from: http://www.sdu. nhs.uk/downloadFile.php?doc_url=1232987735_gmWy_ summary_of_responses.pdf (Cited 28 May 2009.)

10. Sustainable Development Commission and Stockholm Environment Institute. NHS England Carbon Emissions: Carbon footprint study, 2008. London: Sustainable Development Unit; 2008.

11. Pencheon D. Health services and climate change: what can be done? J Health Serv Res Policy 2009; 14(1): 2-4. doi:10.1258/JHSRP.2008.008147

12. Department of Environment and Climate Change NSW. NSW Government Sustainability Policy. South Sydney: ISBN 9781741229417. Available from: http:/www. environment.nsw.gov.au/resources/government/ 08453SustainabilityPolicy.pdf (Cited 22 December 2009.)

13. Department of Environment, Climate Change and Water. Government Energy and Water Efficiency Investment Program Application Form: Environmental Summary; 2008. NSW Government. Available from: http://www.environment.nsw.gov. au/government/geeip.htm (Cited 22 December 2009.)

14. Sydney West Area Health Service. Annual Report 2006/2007. Westmead: Sydney West Area Health Service; 2007.

15. Association of Energy Performance Contractors Australia. What is energy performance contracting? Available from: www.aepca.asn.au (Cited 22 December 2009.)

16. Bresciani E, Wen LM, Rissel C, Alley J, Jochelson T. Promoting active transport: where to start? Environ Health 2002; 2(1): $55-60$.

17. Health Promotion Service. Cycling around the University of Sydney and Royal Prince Alfred Hospital. Camperdown: Sydney South West Area Health Service; 2009. Available from: http://www.cs.nsw.gov.au/pophealth/healthpro/physical/pdf/ RPAH_SydUni_cyclemap.pdf (Cited 29 May 2009.)

18. Daley M, Rissel C, Lloyd B. All dressed up and nowhere to go? A qualitative research study of the barriers and enablers to cycling in inner Sydney. Road and Transport Research 2007; 16(4): $42-52$.

19. Telfer B, Rissel C, Bindon J, Bosch T. Encouraging cycling through a pilot cycling proficiency training program among adults in central Sydney. J Sci Med Sport 2006; 9(1-2): 151-6. doi:10.1016/j.jsams.2005.06.001

20. Rissel C, Telfer B. Managing risk in a workplace bicycle pool. J Australas Coll Road Safety 2005; 16(1): 18-24.

21. Gray M. Climate change is the cholera of our era. Times Online. 25 May 2009. Available from: http://www.timesonline.co.uk/ tol/comment/columnists/guest_contributors/article6355257.ece (Cited 29 May 2009.)

22. McGain F, Blashki GA, Moon KP, Armstrong FM. Mandating sustainability in Australian hospitals. Med J Aust 2009; 190(12): 719-20. 